\title{
ADAPTATION OF ECO-FRIENDLY APPROACH IN THE PRODUCTION OF SOLUBLE POZZOLANIC MATERIAL
}

\author{
ANDRI KUSBIANTORO ${ }^{1}$, RAHIMAH EMBONG ${ }^{1} \&$ NASIR SHAFIQ ${ }^{2}$ \\ ${ }^{1}$ Faculty of Engineering Technology, Universiti Malaysia Pahang. \\ ${ }^{2}$ Department of Civil and Environmental Engineering, Universiti Teknologi PETRONAS.
}

\begin{abstract}
Silica gel made of natural waste materials of sugarcane bagasse has initiated a new trend in pozzolanic area. The employment of eco-friendly approach by using low concentration acids and natural drying via solar heat-based equipment in the pre-treatment process were projected to minimize the energy consumption in producing silica ash. Conversion of ultrafine silica ash from sugarcane bagasse into silica gel was conducted by-using a modified hydrothermal method. $\mathrm{NaOH}$ and $\mathrm{HCI}$ solution were employed in the dissolution and gelification of soluble silica. Analysis on the effect of silica gel in cementitious system was evaluated by including it in mortar specimen as a pozzolan to replace certain portions of Portland cement. Inclusion of additional siliceous gel showed enhancement in the cement hydration process, which resulted in early hardening and the consolidated formation of cement matrix to further contribute in the strength development. Measurement of pozzolanic reactivity of silica gel via Chapelle method verified the active consumption of $\mathrm{Ca}(\mathrm{OH}) 2$ by the soluble silica, which illustrates the possible formation of secondary calcium silicate hydrate (C-S-H) from the pozzolanic reaction. Densification of pore structure via large voids was observed via porosity test at age of 7 and 28 days. Based on the experimental result of this study, silica gel has presented an encouraging prospect to be used as a cement replacement material. Its rapid reaction during the early age would be beneficial in providing early strength properties to the cement-based product.
\end{abstract}

Keywords: eco-friendly, pozzolanic materials, sugarcane bagasse, silica.

\section{INTRODUCTION}

Based on United Nations Environment Programme (UNEP) investigation, about 5 billion metric tons of biomass is generated every year from agriculture [1]. As a result of aggressive agricultural production, the problem will be intensified, since the process will produce biomass that emits methane and leachate and also air pollutants that are generated from open burning during the land clearing process. Therefore, additional roles from other industries are required to consume and utilize these biomass wastes. Development of proper waste treatment technology is also urgently needed, particularly in the developing countries that rely on the agricultural industries for their economic growth, since proper waste management and strong regulatory instruments is generally not yet available in these countries.

Environmental concern related to the disposal issue is the major factor that encourages many researchers to further explore the potential utilization of these by-products, since these materials are commonly resistant to natural degradation [2-4]. A global reduction campaign of $\mathrm{CO}_{2}$ emissions has also encouraged further investigations on the use of supplementary cementitious materials for concrete production [5]. The influence of pozzolanic material in a cementitious system is agreed to be substantial, particularly to the development of calcium 
silicate hydrate framework. Agriculture-based pozzolan has been considered as the most feasible option for the sustainability of cementitious binder.

In the previous researches, most of the researchers merely concentrate on the pozzolanic performance of sugarcane bagasse in its ash form [6-9]. Currently, various attempts have been carried out to further increase the purity of silica from agricultural or industrial by-products [10-12]. One of the methods is by converting siliceous ash into a gel form, which happened to have better pozzolanic performance [13]. Investigations on siliceous gel produced from rice husk and geothermal sludge are presenting better microstructure and thermal performances.

A gelification process in silica gel is commonly started by heating and agitating high-silica ash to form sodium silicate and continued with final conversion into a silica gel form. Hydrochloric acid was chosen as the main chemical in the gelation and acidification of sodium silicate in this process, hence its effectiveness could not be evaluated. Due to the very low bulk density $\left(30.6 \mathrm{~kg} / \mathrm{m}^{3}\right)$ of sugarcane bagasse ash (SCBA), the amount of cement could be replaced by SCBA would be restricted since high volume replacement would result in high water absorption due to the over-dominance of ash volume, which later may lead to insufficient water for hydration process. Therefore, the transformation of SCBA into a gel form is expected to provide a higher amount of cement replacement without compromising the quality of cementitious product.

\section{EXPERIMENTAL METHOD}

In this study, production of soluble pozzolanic substances was based on the extraction of silica from pre-treated sugarcane bagasse. The bagasse was collected as a by-product from cordial juice industry, near Batu Gajah, Perak, Malaysia. The production process involves cleansing, chemical treatment, incineration, and solubilisation. Cleansing of sugarcane bagasse was conducted in a constantly rotating cylinder for a period of 20 minutes and followed by drying process in a self-designed drying chamber.

Drying chamber uses transparent polycarbonate for its external surface hence more heat energy from sunlight can penetrate and trapped inside the chamber. The chamber offers several advantages as compared to conventional electric oven and positively support the entire production process. Table 1 shows the itemized comparison between oven and chamber drying process. Drying chamber was preferred due to the inconsistence oxidation of sugarcane bagasse that may arise from oven drying process. The use of acidic solution in the subsequent chemical treatment process also creates an additional corrosion issue with the oven's interior. Figure 1 shows the drying chamber used in this study and the comparison of sugarcane bagasse dried in oven and chamber.

Table 1: Comparison between oven and chamber drying.

\begin{tabular}{|c|c|c|}
\hline Items & Oven Drying & Chamber Drying \\
\hline Operational cost & Requires electric Fee & $\begin{array}{l}\text { Zero Electric Fee (Sunlight } \\
\text { heat-based) }\end{array}$ \\
\hline $\begin{array}{l}\text { Operating Tem- } \\
\text { perature }\end{array}$ & Maximum $120^{\circ} \mathrm{C}$ & Maximum $70^{\circ} \mathrm{C}$ \\
\hline Acid Issue & $\begin{array}{l}\text { Heavy corrosion at the oven's structure } \\
\text { due to acidic vapour. }\end{array}$ & Negligible \\
\hline SCB Oxidation & $\begin{array}{l}\text { Inconsistence oxidization due to oven's } \\
\text { high humidity }\end{array}$ & Negligible \\
\hline
\end{tabular}



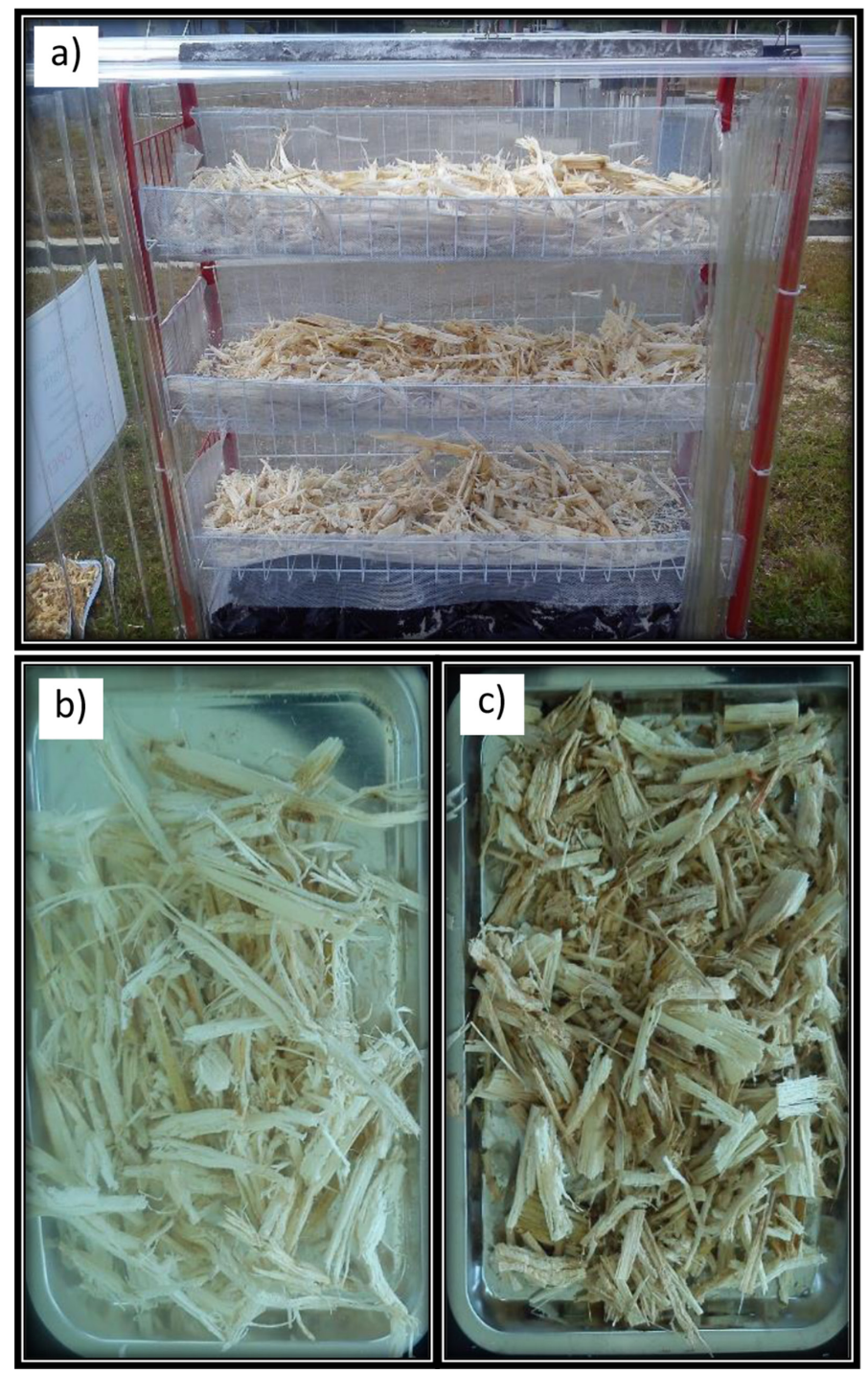

Figure 1: (a) Solar Drying Chamber; (b) Sugarcane bagasse dried in chamber; (c) Sugarcane bagasse dried in oven.

Table 2: Chemical oxide composition of sugarcane bagasse ash (\%).

\begin{tabular}{lllllllllll}
\hline Oxide & $\mathrm{SiO}_{2}$ & $\mathrm{P}_{2} \mathrm{O}_{5}$ & $\mathrm{CaO}$ & $\mathrm{K}_{2} \mathrm{O}$ & $\mathrm{Al}_{2} \mathrm{O}_{3}$ & $\mathrm{SO}_{3}$ & $\mathrm{MgO}$ & $\mathrm{Fe}_{2} \mathrm{O}_{3}$ & $\mathrm{Na}_{2} \mathrm{O}$ & $\mathrm{LOI}$ \\
Percentage (\%) & 84.1 & 7.3 & 2.5 & 2.5 & 0.9 & 0.5 & 1.2 & 0.4 & 0.3 & 0.2 \\
\hline
\end{tabular}

Clean sugarcane bagasse was chemically treated in $0.1 \mathrm{M}$ Hydrochloric acid $(\mathrm{HCl})$ with a soaking period of 1 hour. The treated bagasse was then incinerated in an electronic furnace at $800^{\circ} \mathrm{C}$ for 1 hour to produce reactive siliceous ash. These parameters were obtained from an author's previous study in the chemical treatment of sugarcane bagasse [14]. Table 2 shows the chemical oxide composition of SCBA produced from the incineration process. Production 
of soluble pozzolan from the siliceous ash was conducted using the modified two stages hydrothermal method, which involved the use of sodium hydroxide solution. In the first stage, SCBA was dissolved in $1 \mathrm{M}$ sodium hydroxide $(\mathrm{NaOH})$ solution and heated at boiling temperature for 2 hours. After 2 hours, the solution was cooled down to room temperature and filtered to discard any solid or impurities. In the second stage, $\mathrm{HCl}$ was added and constantly agitated to reduce the $\mathrm{pH}$ of the solution to be lower than 10 and extract the soluble silica.

Measurement on the pozzolanic reactivity of these materials were completed via modified Chapelle test, while their effect in the cementitious specimen was evaluated through the compressive strength properties. In Chapelle test, reduction of $\mathrm{Ca}(\mathrm{OH})_{2}$ was measured based on the presence of silica and/or alumina substance from pozzolanic material. The test would be used to support the hypothesis generated from compressive strength result, where the soluble pozzolans were used as a cement replacement material.

\section{RESULTS AND DISCUSSION}

\subsection{Pozzolanic reactivity analysis}

Conversion of silica ash from the incineration of sugarcane bagasse into soluble silica provides comparable pozzolanic properties with the treated raw SCBA. Nevertheless, it should be noted that the amount of soluble silica includes the weight of silica and its solution. Therefore, higher pozzolanic reactivity is expected for the similar amount of silica in the specimens. Consumption of $\mathrm{Ca}(\mathrm{OH})_{2}$ lead by silica in all siliceous specimen describe the creation of calcium silicate hydrate (C-S-H) structures which act as a secondary C-S-H gel in concrete, mortar, or cement paste.

The presence of these structures in any cement-based framework will provide a positive effect to the mechanical properties via better internal load distribution and the closure of micro voids or interfacial transition zone between aggregate and paste framework. The consumption of $\mathrm{Ca}(\mathrm{OH})_{2}$ would also reduce the possible occurrence of free-lime expansion issue due to the limited amount of lime exist in the system. Figure 2 shows the pozzolanic

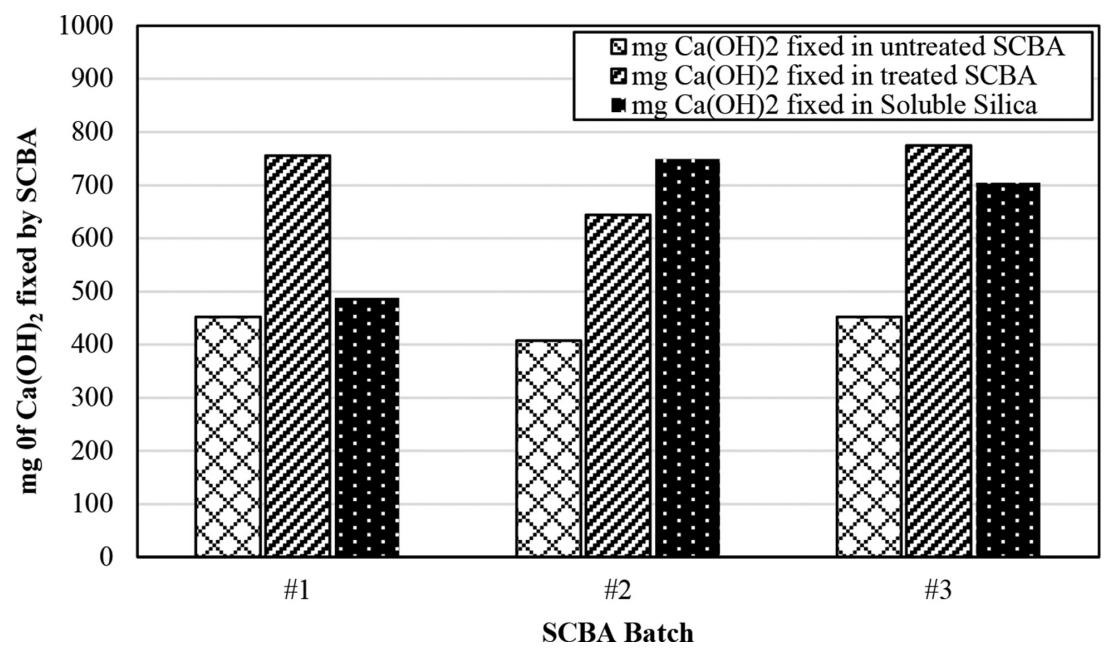

Figure 2: Pozzolanic reactivity of treated, untreated and soluble silica. 
reactivity of each sugarcane-based pozzolan-based on the result of Chapelle test. On average, treatment on a different batch of sugarcane bagasse provided a consistent result where improvement on the pozzolanic reactivity between treated ash and siliceous gel was similarly presented. Nonetheless, change of physical state and bulk density in siliceous gel provided more advantages since larger cement content could be replaced without reducing the workability of the mixture.

\subsection{Compressive strength}

Figure 3 shows the compressive strength development of mortar specimens with the inclusion of untreated ash, treated ash, and soluble silica. These pozzolanic materials replaced $5 \%$ of the amount of cement in the mixture. At this early stage, $5 \%$ was chosen as the replacement percentage due to the very low bulk density characteristic of SCBA, where high volume replacement would occupy a spacious volume in the mixture. The details of mixture proportion used in control specimen was as follows: cement $=390 \mathrm{~kg} / \mathrm{m}^{3}$, water $=280 \mathrm{~kg} / \mathrm{m}^{3}$, and fine aggregate $=1,480 \mathrm{~kg} / \mathrm{m}^{3}$. The water to cement ratio of 0.72 provided mortar specimen with moderate workability, yet considerable reduction was observed after the inclusion of 5\% ashes.

Based on the compressive strength result, early age-strength of non-control specimen followed the conventional pozzolanic trend where the reduction of heat evolution peak by pozzolanic substances reduces the compressive strength development. The phenomenon is explained as the consumption of $\mathrm{Ca}^{2+}$ by $\mathrm{K}^{+}$and $\mathrm{SiO}_{2}$ that would increase the saturation time of ion creating lower peak of heat evolution [15]. A different trend was observed in soluble silica-based specimen where the acceleration on the compressive strength development has taken place since the early age. It is believed that the well-dispersed pozzolanic silica in aqueous medium was able to involve in the hydration process happened in fresh cementitious

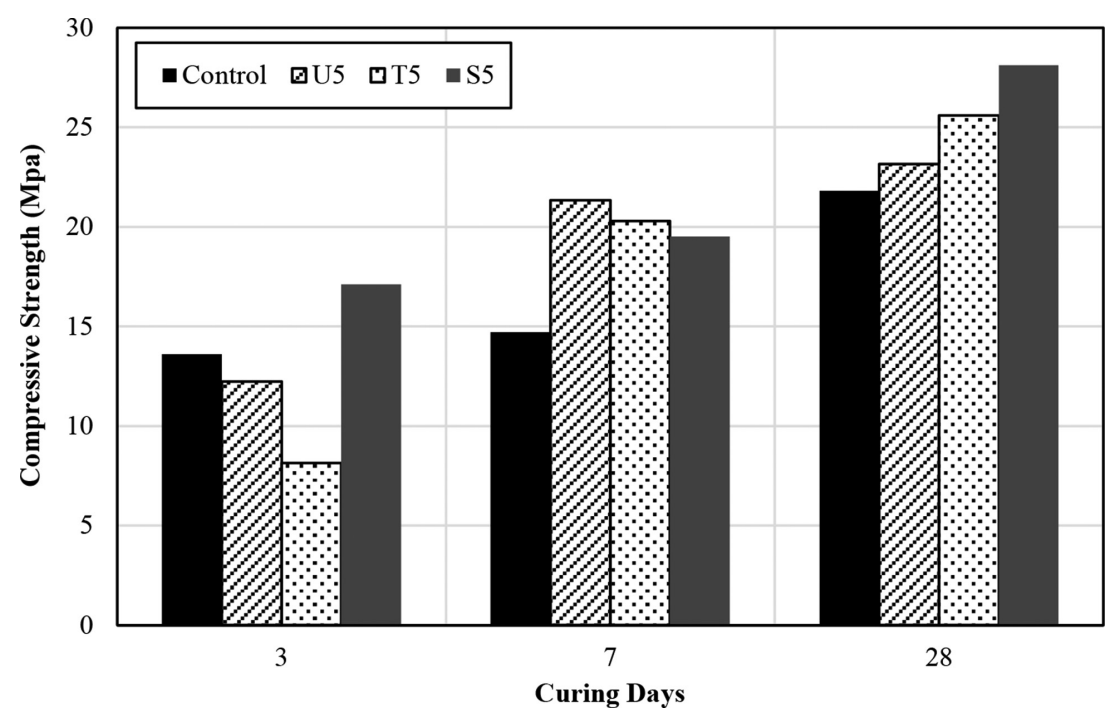

Figure 3: Compressive strength development of mortar containing untreated, treated and soluble silica at $5 \%$ replacement. 
framework $[16,17]$. Immediate production of secondary calcium-silica-hydrate framework constantly enhanced the microstructure of mortar via rapid consolidation of hydrated cement matrix.

\subsection{Field emission scanning electron microscopy analysis}

Microstructural observation conducted on the mortar specimens shows the different characteristic possessed by these specimens. In Fig. 4a, interfacial transition zone of control specimen was dominantly filled with porous matrix. Insufficient hydration product to fill the gaps and micro voids produced a weak framework that reduces the loading distribution support. The existence of ettringite needles in the cement paste framework was also easily detected in control specimen, as shown in Fig. 4 b.

Different characteristic is displayed by soluble pozzolan-based specimen. The existence of micelle-like species was detected in certain parts of the mortar framework (Fig. 4d). These micelle-like structures are generally found in geopolymer framework that utilizes the combination of alumina-silica rich material and sodium silicate solution as the binding material. This nano-sized structure is beneficial in improving the micro properties of mortar or concrete with the enhancement in load distribution mechanism. The closing of interfacial transition zone in this specimen prevented the micro crack path to connect with existing pores in the framework and improved the compressive strength properties.
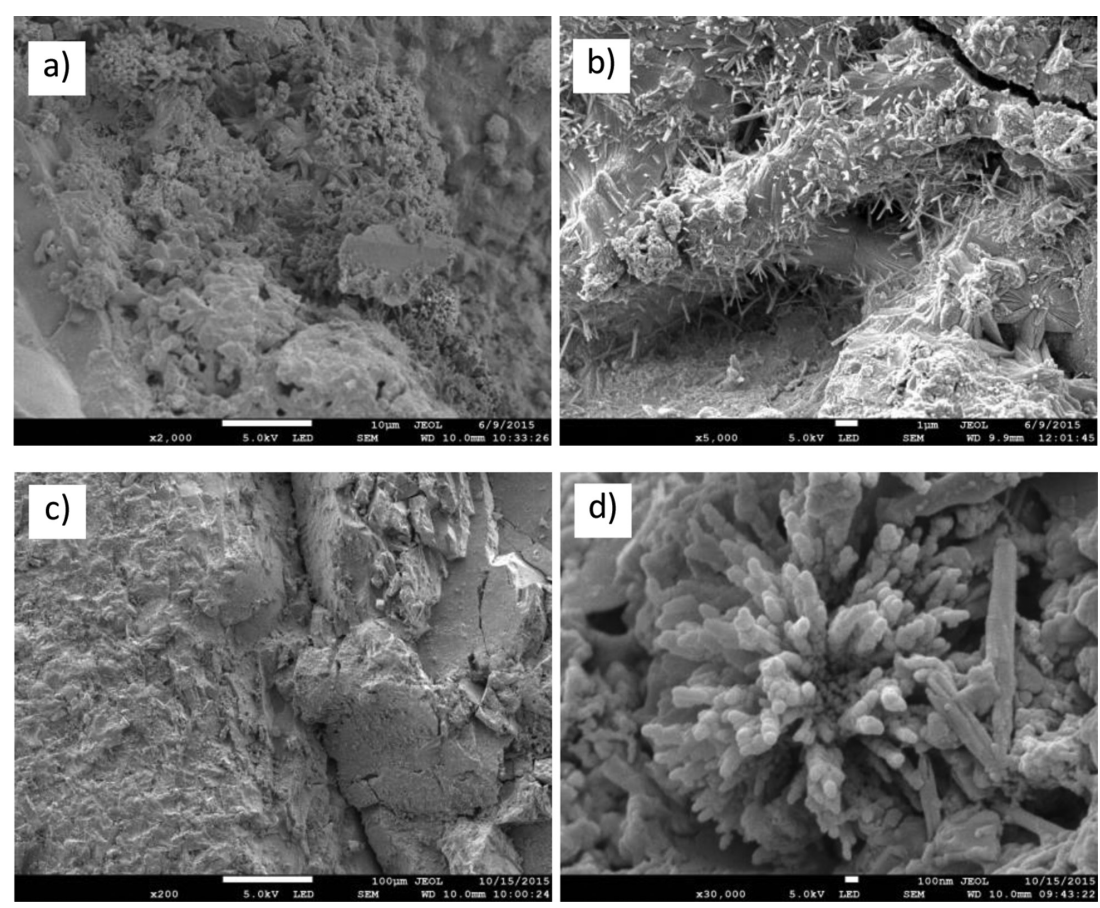

Figure 4: FESEM of (a) ITZ in Control Specimen; (b) Ettringite in Control Specimen; (c) ITZ in Soluble Pozzolan-based Specimen; (d) Micelle-like Structure in Soluble Pozzolan-based Specimen. 


\section{CONCLUSION}

The research work and analysis conducted from different perspective in the pozzolanic properties of soluble silica produced in this study are expected to provide substantial support in the utilization of sugarcane bagasse for cement-based application. The employment of low concentration acids in the pre-treatment process, natural drying via sunlight heat based in the early stage before conversion to soluble silica were projected to minimize the energy consumption in producing pozzolanic material. Based on the experimental works and data analysis conducted in this study, alkali metal leaching using low concentration acid was able to produce white ash containing high purity silica. The process also requires short soaking durations (1 hour) to remove the metallic impurities from the bagasse. Solar drying process incorporated was also able to reduce the energy consumption and prevent the corrosion of the electric oven's panel due to $\mathrm{HCl}$ vapour. The inclusion of soluble silica to replace the cement portion would enhance the cement hydration process, which produce early hardening, consolidated formation of cement matrix, and contribute to the strength development. Therefore, the treatment of sugarcane bagasse by using low $\mathrm{HCl}$ concentration with an assistance from solar drying process proved to be very propitious in producing reactive soluble pozzolan for a cement replacement material purpose.

\section{ACKNOWLEDGEMENT}

The authors would like to thank the financial support from Ministry of Education Malaysia and Universiti Malaysia Pahang (UMP) under research grant RDU130614.

\section{REFERENCES}

[1] United Nations Environment Programme. Focal Areas, Waste Agricultural Biomass, 2015.

[2] Rocha, G.J.M., Nascimento, V.M., da Silva, V.F.N., Corso, D.L.S. \& Gonçalves, A.R., Contributing to the environmental sustainability of the second generation ethanol production: delignification of sugarcane bagasse with sodium hydroxide recycling. Industrial Crops and Products, 59, pp. 63-68, 2014. http://dx.doi.org/10.1016/j.indcrop.2014.05.002

[3] Rukzon, S. \& Chindaprasirt, P., Utilization of bagasse ash in high-strength concrete. Materials \& Design, 34, pp. 45-50, 2012. http://dx.doi.org/10.1016/j.matdes.2011.07.045

[4] Singh, K.J. \& All Jawald, S.M., Utilization of sugarcane bagasse ash (SCBA) as pozzolanic material in concrete. A Review. IJBSTR, 1, pp. 42-44, 2013.

[5] Turgut, P., Manufacturing of building bricks without Portland cement. Journal of Cleaner Production, 37, pp. 361-367, 2012. http://dx.doi.org/10.1016/j.jclepro.2012.07.047

[6] Kanraj, D., Baharudeen, A., Dev, V.G. \& Santhanam, M., Performance evaluation of sugarcane bagasse ash blended cement in concrete. Cement and Concrete Composites, 59, pp. 77-88, 2015. http://dx.doi.org/10.1016/j.cemconcomp.2015.03.004

[7] Shafig, N., Hussein, A.A.E., Nuruddin, M.F. \& Memon, F.A., Compressive strength and microstructure of sugarcane bagasse ash in concrete. Journal of Applied Sciences, Engineering and Technology, 7(12), pp. 2569-2577, 2014. 
[8] Toledo Filho, R.D., Cordeiro, G.C., Tavarse, L.M. \& Fairbairn, E.M., Ultrafine grinding of sugarcane bagasse ash for application as pozzolanic admixture in concrete. Cement and Concrete Research, 39(2), pp. 110-115, 2009. http://dx.doi.org/10.1016/j.cemconres.2008.11.005

[9] Sales, A. \& Lima, S.A., Use of Brazilian sugarcane bagasse ash in concrete as sand replacement. Waste Management, 30(6), pp. 1114-1122, 2010. http://dx.doi.org/10.1016/j.wasman.2010.01.026

[10] Riding, K.A. \& Ataie, F.F., Impact of pretreatments and enzymatic hydrolysis on agricultural residue ash suitability for concrete. Construction and Building Materials, 58, pp. 25-30, 2014. http://dx.doi.org/10.1016/j.conbuildmat.2014.01.099

[11] Wyman, C.E. \& Jacobsen, S.E., Cellulose and hemicellulose hydrolysis models for application to current and novel pretreatment processes. Applied Biochemical Biotechnology, 84, pp. 81-96, 2000.

[12] Johar, N., Ahmad, I. \& Dufresne, A., Extraction, preparation and characterization of cellulose fibres and nanocrystals from rice husk. Industrial Crops and Products, 37(1), pp. 93-99, 2012.

http://dx.doi.org/10.1016/j.indcrop.2011.12.016

[13] Setyawan, H., Muljani, S., Wibawa, G. \& Altway, A., A facile method for the production of high-surface-area mesoporous silica gels from geothermal sludge. Advanced Powder Technology, 25(5), pp. 1593-1599, 2014. http://dx.doi.org/10.1016/j.apt.2014.05.012

[14] Embong, R., Shafiq, N., Kusbiantoro, A. \& Nuruddin, M.F., Effectiveness of low concentration acid and solar drying as pre-treatment features for producing pozzolanic sugarcane bagasse ash. Journal of Cleaner Production, 112, pp. 953-962, 2016. http://dx.doi.org/10.1016/j.jclepro.2015.09.066

[15] Hwang, C.L., The Use of Rice Husk Ash in Concrete. Waste Materials Used in Concrete Manufacturing, ed. S. Chandra, Noyes Publication: USA, p. 198, 1997.

[16] Govindarajan, D. \& Jayalakshmi, G., XRD, FTIR and Microstructure studies of calcined sugarcane bagasse ash. Advances in Applied Science Research, 2(3), pp. 544-549, 2011.

[17] Lima, S.P.B.D., Vasconcelos, R.P.D., Paiva, O.A., Cordeiro, G.C., Chaves, M.R.D.M., Toledo Filho, R.D. \& Fairbairn, E.D.M.R., Production of silica gel from residual rice husk ash. Journal of Quimica Nova, 34(1), pp. 71-75, 2011.

http://dx.doi.org/10.1590/S0100-40422011000100014 